\title{
Vitamin D Receptor Polymorphisms in Children with Chronic Immune Thrombocytopenic Purpura
}

\author{
Mervat Abd-Allah Hesham¹, Laila Metwaly Sherif ${ }^{1}$, Aml Fawzy Abd-Elmaaguid ${ }^{2}$, \\ Shehab Mohamed Nageeb Mohamed Saad ${ }^{1}$ \\ Departments of ${ }^{1}$ Pediatrics , ${ }^{2}$ Biochemistry, Faculty of Medicine - Zagazig University \\ *Corresponding author: Shehab Mohamed Nageeb Mohamed Saad, Mobile: (+20)01024683929,
}

E-mail: mosad8rashed@gmail.com

\begin{abstract}
Background: Primary immune thrombocytopenia (ITP) is an autoimmune disorder characterized by autoantibodymediated-enhanced platelet destruction. Chronic ITP was defined as thrombocytopenia persisting for more than 12 months. Previous studies have found that vitamin D receptor (VDR) polymorphisms are associated with the incidence and severity of certain autoimmune diseases.

Objective: This study aimed to detect the frequency and role of VDR gene polymorphisms on pathogenesis of chronic ITP in children. Patients and methods: A case control study that was conducted at Hematology Unit of Pediatric, Medical Biochemistry and Molecular Biology Departments at Zagazig University Hospital during a period from November 2017 until November 2018. The study was conducted on 40 participants divided into two groups: case group including 20 children with chronic ITP (8males and 12 females) and control group including 20 age- and sexmatched healthy children (6males and 14females).

Results: This study showed that the patients' group had a lower serum vitamin D level than the control group with a statistical significant difference $(24.2 \pm 9.64 \mathrm{ng} / \mathrm{ml}$ and $33.75 \pm 11.1 \mathrm{ng} / \mathrm{ml}$ respectively). There was also a highly significant difference between chronic ITP cases and control regarding distribution of SNP of VDR gene (Cdx2) where GG was founded in $65 \%$ of ITP cases versus $35 \%$ in control. Also, AA was founded in $30 \%$ of control versus $5 \%$ of cases. Conclusion: Vitamin D receptor gene ( $\mathrm{Cdx} 2)$ polymorphism was found to be associated with higher incidence of chronic childhood immune thrombocytopenic purpura. Also chronic ITP in children was found to be associated with lower level of serum vitamin D.
\end{abstract}

Key words: ITP, Vitamin D, Association.

\section{INTRODUCTION}

Childhood Immune thrombocytopenia (ITP) is one of the most common benign hematologic disorders. It is characterized by isolated, immune-mediated thrombocytopenia. The etiologies of ITP are unclear but are likely genetic or acquired factors ${ }^{(\mathbf{1})}$. Moreover, ITP is considered an autoimmune syndrome involving antibody-and cell-mediated destruction of platelets and suppression of platelet production that may predispose to bleeding. Recent recommendations suggest that ITP might be used to designate all cases of immunemediated thrombocytopenia whether primary or secondary (2). Chronic ITP was defined as thrombocytopenia persisting for more than 12 month with normal or increased marrow megakaryocytes and no secondary immune or non-immune abnormalities that could account for the thrombocytopenic state. The severity of bleeding tendency and thrombocytopenia was assessed according to the previously described criteria ${ }^{(3)}$.

Vitamin D act via binding to an intramuscular receptor, vitamin D receptor (VDR), present in target tissues and cells. This receptor belongs to the super family of transacting transcriptional regulatory factors (4). Vitamin D receptor binds to 1, 25-hydroxy vitamin $\mathrm{D}$, which is the active form of vitamin $\mathrm{D}$, and mediates its biological activity. The VDR gene is located on chromosome 12q13.1, and it has several polymorphic regions ${ }^{(5)}$.

More than 30 different human tissues such as the brain, heart, stomach, pancreas, lymphatics, skin, gonads, and prostate tissue are composed of cells including $\mathrm{T}$ and $\mathrm{B}$ lymphocytes that express the VDR (6). Previous studies have found that VDR polymorphisms are associated with the incidence and severity of certain autoimmune diseases ${ }^{(7)}$. In humans and animals lacking vitamin $\mathrm{D}$ receptor polymorphism (VDR) function or lacking vitamin D offer insight into the immunological functions of vitamin D. Expression of VDR by immune system cells suggest that vitamin D influences immune system function ${ }^{(8)}$. Over 470 common single nucleotide polymorphisms (SNPs) have been identified in the VDR gene ${ }^{(9)}$.

These polymorphisms modulate the activity of the VDR gene and their frequency differs across multiethnic groups. The $\mathrm{Cdx}-2$ polymorphism is located in the promoter region of VDR, and it carries a G to A sequence change that affects the function of the transcription factor ${ }^{(\mathbf{1 0})}$.

In caucasians, several common allelic variants have been studied: 1) $\mathrm{Cdx}-2$ (a single base change $\mathrm{G}$ to A, located upstream in the 5' UTR of the gene) that significantly alters the transcriptional activity of the VDR promoter region. 2) FokI (a single base change C 
to $\mathrm{T}$, located in promoter region 5 ' of exon 2) that leads to the synthesis of a longer protein that is less effective as a transcriptional activator of VDR. 3) BsmI (a single base change $\mathrm{G}$ to $\mathrm{A}$, located in the last intron). 4) ApaI (a single base change Gto $\mathrm{T}$, located in the last intron) that affects mRNA stability and translational activity of VDR, and 5) TaqI (a single base change $\mathrm{C}$ to $\mathrm{T}$, located in exon 9) that leads to silent codon generation ${ }^{(11)}$.

This study aimed at detection of the frequency and role of VDR gene polymorphisms on pathogenesis of chronic ITP in children.

\section{PATIENTS AND METHODS}

A case control study was conducted at Hematology Unit of Pediatric Department, Medical, Biochemistry and Molecular Biology Departments at Zagazig University Hospital during a period from November 2017 until November 2018. The study included 40 participants divided into two groups: case group including 20 children with chronic ITP ( 8 males and 12 females) with mean age of $5.62 \pm 1.91$ years and control group including 20 age- and sex-matched healthy children (6 males and 14 females) with mean age of $5.17 \pm 1.75$ years.

Inclusion Criteria: Children with chronic immune thrombocytopenic purpura, aged between 3 and 15 year and idiopathic thrombocytopenic purpura persistent more than 12 month.

Exclusion Criteria: Persistent/acute immune thrombocytopenic purpura, concomitant chronic disease and stabilized or not secondary immune thrombocytopenic purpura.

All children were subjected to detailed history with emphasis on disease duration, history of drugs intake such as steroids that nearly most of patients started by oral steroids or iv solumedrol at first and shifted to other line regimen of treatment such as intravenous immunoglobulins (IVIG) or eltrombopag in case of no or poor response and history of bleeding (skin, mucus membrane, frank bleeding). Complete clinical examination including site and shape of bleeding. Laboratory investigations including complete blood count with manual platelet count and bone marrow examination. Also, laboratory investigations to exclude secondary causes (C3, ANA, antiDNase) from medical records. Specific investigations including serum 25hydroxy vitamin D [25(OH) D]: $2 \mathrm{ml}$ venous blood was collected in serum collecting tube to measure vit D and genotype (ELISA kit supplied by DRG International, Inc. USA) according to manufacturer's instructions

VDR polymorphisms detection "CDX": One milliliter peripheral venous blood samples were collected in sterile tubes containing EDTA for DNA extraction. Five common VDR SNP were selected, and SNP at VDR restriction sites Cdx-2 (rs11568820).

Genomic DNA was extracted from whole blood using the commercially available G-spin TM Total DNA Extraction Kit (iNtron bio-tehnology, Seongnam-Si,
Korea).

The method of Fang et al. ${ }^{(12)}$ was modified for the amplification of the Cdx-2 SNP (rs11568820). The PCR amplification was carried out in a $10-\mu \mathrm{L}$ total volume with $1 \mu \mathrm{L}$ of 0.8 to $1.2 \mu \mathrm{mol} / \mathrm{L}$ of each of the primers G-For (5'AGGATAGAGAAAATAATAGAAAACATT-3') and A-Rev (5'-ACGTTAAGTTCAGAAAGATTAATTC$\left.3^{\prime}\right)$ and $1 \mu \mathrm{L}$ of $1.2 \mu \mathrm{mol} / \mathrm{L}$ of each of the primers GRev (5'-AACCCATAATAAGAAATAAGTTTTTAC$\left.3^{\prime}\right)$ and A-For(5'-TCCTGAGTAAACTAGGTCA CAA-3'), $5 \mu$ L of GoTaq Green Master Mix (Promega) and approximately $50 \mathrm{ng}$ of DNA. Thermo cycling was carried out as above with an initial denaturation at $96^{\circ} \mathrm{C}$ for 5 minutes; followed by 30 cycles of denaturation at $94^{\circ} \mathrm{C}$ for 45 seconds, annealing at $56^{\circ} \mathrm{C}$ for 45 seconds, extension at $72^{\circ} \mathrm{C}$ for 45 seconds and a final extension at $72^{\circ} \mathrm{C}$ for 5 minutes. The PCR products were separated by electrophoresis in a $2.5 \%$ agarose gel in $0.5 \times$ Tris borate EDTA at $120 \mathrm{~V}$ for 1 hour.

\section{Ethical considerations:}

Written informed consent for participation in the study was obtained from the patient' parents. Approval was received from the Pediatric Department, Zagazig University Hospitals for conducting the study after the approval of the Institutional Review Board (IRB). The work was carried out for human studies in accordance with the World Medical Association's code of Ethics (Deceleration of Helsinki).

\section{Statistical analysis:}

The collected data were tabulated and analyzed using SPSS version 24 software (Spss Inc, Chicago, ILL Company). Categorical data were presented as number and percentages. Chi square test $\left(\mathrm{X}^{2}\right)$, or Fisher's exact test (FET) were used to analyze categorical variables. Quantitative data were tested for normality using Kolomogrov Smirnove test assuming normality at $\mathrm{P}>0.05$. The accepted level of significance in this work was stated at $0.05(\mathrm{P} \leq 0.05$ was considered significant), $\mathrm{P}$ value $>0.05$ is non-significant $(\mathrm{N}-\mathrm{S})$.

\section{RESULTS}

Table (1): Initial bleeding symptoms distribution among cases

\begin{tabular}{|l|c|c|}
\hline Patient bleeding symptoms & Case No & \% \\
\hline Ecchymosis & 9 & 45.0 \\
\hline $\begin{array}{l}\text { Ecchymosis + gum } \\
\text { bleeding }\end{array}$ & 4 & 20.0 \\
\hline Ecchymosis+ epistaxis & 6 & 30.0 \\
\hline Epistaxis & 1 & 5.0 \\
\hline Total & 20 & 100.0 \\
\hline
\end{tabular}

Regarding presenting symptoms and initial bleeding, our results showed that ecchymosis was the most presenting symptoms of initial bleeding in 95\% (19 patients) of the cases and one patient was presented with epistaxis only. Of those 19 patients; 4 (20.0\%) patients 
were also presented with gum bleeding and $6(30.0 \%)$

patients with epistaxis (Table 1).

Table (2): Distribution of cases regarding treatment

\begin{tabular}{|l|c|c|}
\hline \multicolumn{1}{|c|}{ Treatment } & No & \% \\
\hline Oral steroid & 20 & 100.0 \\
\hline Solumedrol & 20 & 100.0 \\
\hline IVIG & 13 & 65.0 \\
\hline Eltrombopag & 6 & 30.0 \\
\hline Total & 20 & 100.0 \\
\hline
\end{tabular}

The results showed that $100 \%$ (20 patients) were given oral steroids and solumedrol, 65\% (13 patients) were given intravenous immunoglobulin (IVIG) and only 6 patients (30.0\%) were given thrombopoietin receptor agonists (Eltrombopag) (Table 2).

Table (3): Complete Blood Count Distribution among cases

\begin{tabular}{|l|l|c|c|c|c|}
\hline \multicolumn{2}{|l|}{ CBC } & Cases & PLT & t & P \\
\hline HB & Mean \pm SD & $10.22 \pm 1.19$ & $10.54 \pm 1.85$ & -1.025 & 0.298 \\
\hline PLT & Mean \pm SD & $9.9 \pm 8.4$ & $191.25 \pm 27.1$ & -27.75 & $0.00 * *$ \\
\hline WBCs & Mean \pm SD & $8.26 \pm 1.98$ & $8.34 \pm 2.32$ & -0.897 & 0.458 \\
\hline
\end{tabular}

Single drug treatment regimen was given in every attack not combined treatment regimen and the duration of the drug given was according to the drug choice regimen such as iv solumedrol as a pulse steroid for three days then oral steroids for two to four weeks regarding tapering of the dose. If we start with IVIG, we give for one to two days. In case of shifting or starting with eltrombopag, we give this drug for four to six weeks with cautious monitoring of kidney and liver functions. As regards complete blood count analysis, the obtained study showed significant decrease of platelets count in cases compared to control group $\left(9.9 \pm 8.4 \times 10^{3} / \mathrm{mm}^{3}\right.$ and $191.25 \pm 27.1 \times 10^{3} / \mathrm{mm}^{3}$ respectively). However, there was non-significant decrease in hemoglobin and leukocytic count in cases compared to control group (Table 3).

Table (4): Frequency of VDR genotype and Allele distribution among studied groups

\begin{tabular}{|c|c|c|c|c|c|c|c|c|}
\hline \multirow{2}{*}{\multicolumn{3}{|c|}{ (2) }} & \multicolumn{2}{|c|}{ Group } & \multirow{2}{*}{ Total } & \multirow{2}{*}{$\mathbf{X}^{2}$} & \multirow{2}{*}{$\mathbf{P}$} & \multirow{2}{*}{ OR (CI 95\%) } \\
\hline & & & Control & Case & & & & \\
\hline \multirow{6}{*}{ Genotype } & \multirow{2}{*}{$\mathbf{A A}$} & $\mathbf{N}$ & 6 & 1 & 7 & \multirow{2}{*}{17.81} & \multirow{2}{*}{$0.00 * *$} & \multirow{2}{*}{$\begin{array}{c}\text { AA } \\
0.12(0.01-2.71)\end{array}$} \\
\hline & & $\%$ & $30.0 \%$ & $5.0 \%$ & $17.5 \%$ & & & \\
\hline & \multirow{2}{*}{ GA } & $\mathbf{N}$ & 7 & 6 & 13 & \multirow{2}{*}{0.38} & \multirow{2}{*}{0.53} & \\
\hline & & $\%$ & $35.0 \%$ & $30.0 \%$ & $32.5 \%$ & & & \\
\hline & \multirow{2}{*}{ GG } & $\mathbf{N}$ & 7 & 13 & 20 & \multirow{2}{*}{9.1} & \multirow{2}{*}{$0.002 *$} & GG \\
\hline & & $\%$ & $35.0 \%$ & $65.0 \%$ & $50.0 \%$ & & & $3.45(0.79-15.8)$ \\
\hline \multirow{4}{*}{ Allele } & \multirow{2}{*}{$\mathbf{A}$} & $\mathbf{N}$ & 19 & 8 & 27 & \multirow{4}{*}{6.74} & \multirow{4}{*}{$0.009 *$} & \multirow{4}{*}{$\begin{array}{c}\mathrm{G} \\
3.6(1.2-11.07)\end{array}$} \\
\hline & & $\%$ & $47.0 \%$ & $20.0 \%$ & $33.7 \%$ & & & \\
\hline & \multirow{2}{*}{ G } & $\mathbf{N}$ & 21 & 32 & 53 & & & \\
\hline & & $\%$ & $53.0 \%$ & $80.0 \%$ & $66.3 \%$ & & & \\
\hline
\end{tabular}

Table (4) showed a highly significant difference between chronic ITP cases and control regarding distribution of SNP of VDR gene (Cdx2) where GG was founded in 65\% of ITP cases versus 35\% in control. Also, AA was founded in $30 \%$ of control versus 5\% of cases. Regarding the frequency of the Cdx-2 alleles in the studied groups, the A allele was presented in $19(47.0 \%)$ and the $\mathrm{G}$ allele was presented in $21(53.0 \%)$ in control group, While in cases group the A allele was presented in 8 (20.0\%) cases and the $\mathrm{G}$ allele was presented in $32(80 \%)$ of cases.

Table (5): Vitamin D level distribution among studied groups 


\begin{tabular}{|c|c|c|c|c|c|c|}
\hline & & & Case $(\mathrm{N}=20)$ & Control $(\mathrm{N}=20)$ & Mann Whitney/X & $\mathbf{P}$ \\
\hline \multicolumn{3}{|c|}{ VIT D Level ng/ml } & $24.2 \pm 9.64$ & $33.75 \pm 11.1$ & -2.41 & $0.021^{*}$ \\
\hline \multirow{4}{*}{$\begin{array}{l}\text { Vitamin D } \\
\text { status }\end{array}$} & \multirow{2}{*}{ Deficient } & $\mathrm{N}$ & 11 & 8 & \multirow{4}{*}{0.9} & \multirow{4}{*}{0.34} \\
\hline & & $\%$ & $55.0 \%$ & $40.0 \%$ & & \\
\hline & \multirow{2}{*}{ Sufficient } & $\mathrm{N}$ & 9 & 12 & & \\
\hline & & $\%$ & $45.0 \%$ & $60.0 \%$ & & \\
\hline \multirow{2}{*}{\multicolumn{2}{|c|}{ Total }} & $\mathrm{N}$ & 20 & 20 & & \\
\hline & & $\%$ & $100.0 \%$ & $100.0 \%$ & & \\
\hline
\end{tabular}

Table (5) showed that the patients' group had a lower serum vitamin D level than that of the control group with a statistical significant difference $(24.2 \pm 9.64 \mathrm{ng} / \mathrm{ml}$ and $33.75 \pm 11.1 \mathrm{ng} / \mathrm{ml}$ respectively).

Table (6): Relation between VIT D level and different genotypes among studied groups

\begin{tabular}{|l|l|l|c|c|c|c|c|c|}
\hline \multicolumn{2}{|l}{ Group } & N & Mean & td. Deviation & Minimum & Maximum & $\begin{array}{c}\text { Kruskal } \\
\text { Walis }\end{array}$ & P \\
\hline \multirow{3}{*}{ Control } & GG & 7 & 34.4286 & 8.07885 & 25.00 & 42.00 & & \\
\cline { 2 - 9 } & GA & 7 & 29.2857 & 10.29636 & 14.00 & 53.00 & \multirow{2}{*}{0.87} & 0.43 \\
\cline { 2 - 8 } & AA & 6 & 38.1667 & 11.83920 & 22.00 & 51.00 & & \\
\hline \multirow{3}{*}{ Case } & GG & 13 & 25.9231 & 11.98488 & 5.00 & 44.00 & \multirow{3}{*}{0.51} & 0.606 \\
\cline { 2 - 8 } & GA & 6 & 22.3333 & 12.82652 & 8.00 & 32.00 & & \\
\cline { 2 - 7 } & AA & 1 & 17.0000 &. & 13.00 & 13.00 & & \\
\hline
\end{tabular}

Table (6) showed that there was no significant relation between different genotypes and the mean levels of serum vitamin D among the studied groups.

Table (7): Correlation of vitamin D with age, HB, WBCs and PLT

\begin{tabular}{|c|c|c|}
\hline & & VIT D Level ng/ml \\
\hline \multirow{2}{*}{ Age } & $\mathrm{r}$ & -0.137 \\
\hline & $\mathrm{P}$ & 0.399 \\
\hline \multirow{2}{*}{ HB } & $\mathrm{r}$ & 0.053 \\
\hline & $\mathrm{P}$ & 0.825 \\
\hline \multirow{2}{*}{ Platelet } & $\mathrm{r}$ & -0.103 \\
\hline & $\mathrm{P}$ & 0.664 \\
\hline \multirow{2}{*}{ WBCs } & $\mathrm{r}$ & -0.021 \\
\hline & $\mathrm{P}$ & 0.929 \\
\hline
\end{tabular}

Table (8): Relation between different VDR genotypes and age, HB, WBCs and PLT

\begin{tabular}{|c|c|c|c|c|c|c|c|c|c|}
\hline \multirow{2}{*}{\multicolumn{4}{|c|}{ Group }} & \multicolumn{3}{|c|}{ Genotype } & \multirow{3}{*}{$\begin{array}{c}\text { Total } \\
12\end{array}$} & \multirow{2}{*}{$X^{2}$} & \multirow{2}{*}{$\mathbf{P}$} \\
\hline & & & & \multirow{2}{*}{$\begin{array}{c}\mathbf{A A} \\
6 \\
\end{array}$} & \multirow{2}{*}{\begin{tabular}{|c|} 
GA \\
3 \\
\end{tabular}} & \multirow{2}{*}{$\begin{array}{c}\text { GG } \\
3 \\
\end{array}$} & & & \\
\hline \multirow{6}{*}{ Control } & \multirow{4}{*}{ Sex } & & $\mathrm{N}$ & & & & & \multirow{4}{*}{5.74} & \multirow{4}{*}{0.058} \\
\hline & & $F$ & $\%$ & $100.0 \%$ & $42.9 \%$ & $42.9 \%$ & $60.0 \%$ & & \\
\hline & & \multirow{2}{*}{$\mathbf{M}$} & $\mathrm{N}$ & 0 & 4 & 4 & 8 & & \\
\hline & & & $\%$ & $0.0 \%$ & $57.1 \%$ & $57.1 \%$ & $40.0 \%$ & & \\
\hline & \multirow{2}{*}{\multicolumn{2}{|c|}{ Total }} & $\mathrm{N}$ & 6 & 7 & 7 & 20 & & \\
\hline & & & $\%$ & $100.0 \%$ & $100.0 \%$ & $100.0 \%$ & $100.0 \%$ & & \\
\hline \multirow{6}{*}{ Cases } & \multirow{4}{*}{ Sex } & & $\mathrm{N}$ & 1 & 4 & 9 & 14 & \multirow{4}{*}{0.46} & \multirow{4}{*}{0.79} \\
\hline & & $F$ & $\%$ & $100.0 \%$ & $66.7 \%$ & $69.2 \%$ & $70.0 \%$ & & \\
\hline & & \multirow{2}{*}{$\mathbf{M}$} & $\mathrm{N}$ & 0 & 2 & 4 & 6 & & \\
\hline & & & $\%$ & $0.0 \%$ & $33.3 \%$ & $30.8 \%$ & $30.0 \%$ & & \\
\hline & \multirow{2}{*}{\multicolumn{2}{|c|}{ Total }} & $\mathrm{N}$ & 1 & 6 & 13 & 20 & & \\
\hline & & & $\%$ & $100.0 \%$ & $100.0 \%$ & $100.0 \%$ & $100.0 \%$ & & \\
\hline
\end{tabular}

Table $(7,8)$ showed that there were no significant relation between vitamin D level or different VDR genotypes and age, gender and complete blood picture (CBC) values ( $\mathrm{Hb} \%$, WBCs and PLT). 
Childhood immune thrombocytopenic purpura (ITP) is characterized by isolated, immunemediated thrombocytopenia. The etiology of ITP is unclear but is likely due to genetic or acquired factors (13). Acquired factors most often consist of immunological problems such as cross-reactive antibodies against platelet membrane glycoproteins that are produced during viral infections such as rubella, varicella, mumps, cytomegalovirus and Epstein-Barr virus ${ }^{(7)}$.

Vitamin D has an important influence on the host's immune system by modulating both innate and adaptive immunity and regulating the inflammatory cascade $^{(14)}$.

Many studies found that Vitamin D receptor polymorphisms are associated with the incidence and severity of certain autoimmune diseases (7).

Regarding the initial presenting symptoms, the observed results showed that ecchymosis was the most presenting symptoms of initial bleeding in 95\% (19 patients) of the cases and one patient was presented with epistaxis only. Of those 19 patients; 4 (20.0\%) patients were also presented with gum bleeding, $6(30.0 \%)$ patients were also presented by epistaxis. Our results are in agreement with Evim et al. ${ }^{(15)}$ who reported in their study on 201 children to evaluate the data of children with ITP by using the new definitions of the International Working Group (IWG) on ITP, that the most frequent symptoms were petechiae and ecchymosis (71\%). Thirty-six children (18\%) were admitted with epistaxis and/or gum bleeding along with petechiea and ecchymosis. Twenty-three patients $(11 \%)$ had no bleeding manifestations. Also, we agree with what was reported by Saeidi et al. ${ }^{(16)}$ that the prevalence of initial symptoms including petechiae and ecchymosis was $60.5 \%$ and $61 \%$, respectively in all patients, but severe bleeding rarely occurred.

Regarding complete blood count analysis, this study showed isolated thrombocytopenia with mean PLT $9.9 \pm 8.4$ ranging between $2-34 \times 10^{9} / \mathrm{L}$. The mean hemoglobin concentrations in the cases was $10.22 \pm 1.19$ ranging between 8.1-12. Anemia occurred in some cases due to severe bleeding. Also, the leukocytic count was normal in the cases with mean WBCs level $8.26 \pm 1.98$ ranging between 4.9-12.3. Elevated leukocytic count occurred in some cases due to presence of infection.

All studies and guidelines were based on that ITP is characterized by isolated thrombocytopenia with an otherwise normal complete blood count. Anemia from blood loss may be present, but it should be proportional to the amount, and the duration, of bleeding and may result in iron deficiency (evidence level IV). If anemia is found, the reticulocyte count may help define whether it the result of poor production or increased destruction of red blood cells (RBCs) ${ }^{(17,18,19)}$.
Regarding therapy given to the patients, the current study showed that $100 \%$ (20 patients) were given oral steroids and solumedrol, 65\% (13 patients) were given intravenous immunoglobulin (IVIG) and only 6 patients $(30.0 \%)$ were given thrombopoietin receptor agonists. In the study done by Evim et al. ${ }^{(15)}$ IVIG was administered to $66(65 \%)$ children, whereas $36(35 \%)$ received corticosteroids as the first therapeutic choice. While in the study done by Saeidi et al. ${ }^{(16)} 86$ patients $(26.6 \%)$ received only methylprednisolone, 15 (4.6\%) received IVIG, $207(64.1 \%)$ received both drugs and 15 (4.6\%) received none. Grimaldi-Bensouda et al. ${ }^{(20)}$ reported in their study on 257 children aged 6 months18 years and diagnosed with primary ITP, 208 (80.9\%) patients started initial treatment while the other 49 (19.1\%) underwent watchful waiting strategy. Of the 208 patients, $63 / 208(30.3 \%)$ were initially treated with corticosteroids alone, 99/208 (47.6\%) were initially treated with intravenous immunoglobulin (IVIG) alone while 46/208 (22.1\%) were initially treated with corticosteroids and IVIG.

Regarding serum vitamin D level in the participants, our study proved that the patients' group had a lower serum vitamin $D$ level than that of the control group with a statistical significant difference $(24.2 \pm 9.64 \mathrm{ng} / \mathrm{ml}$ and $33.75 \pm 11.1 \mathrm{ng} / \mathrm{ml}$ respectively $)$. The results of this study are in agreement with Čulić $\boldsymbol{e t}$ al. ${ }^{(14)}$ who reported in their study on 21 child who were recruited from both chronic ITP patients and newly diagnosed ITP, that VD deficiency (values $<75 \mathrm{nmol} / \mathrm{L}$ ) was detected in 11 patients with newly diagnosed ITP, and seven patients with chronic ITP. Only three patients with newly diagnosed and none with chronic ITP had normal VD values. Newly diagnosed ITP patients had statistically significantly higher values $(\mathrm{P}<.044)$ of VD than the patients with chronic type of ITP.

Regarding correlation between serum vitamin level and some variables in the study, our results showed that there was no significant correlation between serum vitamin $\mathrm{D}$ level and age $(\mathrm{r}=-0.137 \& \mathrm{p}=0.399)$, $\mathrm{Hb} \%(\mathrm{r}=0.053 \& \mathrm{p}=0.825)$, platelets $(\mathrm{r}=-0.103 \& 0.664)$ and WBCs $(\mathrm{r}=-0.021 \& 0.929)$. Also, there was no significant difference between male participants and female participants regarding serum vitamin D level. This can be explained by the vast majority of the participants lived in the same geographic area and the blood samples were taken in the same season.

Regarding the three $\mathrm{Cdx}-2$ genotype distribution in the participants, these results illustrated that in the cases' group, the most presented genotype was the GG genotype in 13 (65.0\%) patients followed by Ga genotype in $6(30.0 \%)$ and the genotype AA in 1 $(5.0 \%)$ patient. While in the control group both GG and GA genotypes were presented in 7 (35.0\%) cases for each and the AA genotype was present in $6(30.0 \%)$ children. 
Regarding the frequency of the $\mathrm{Cdx}-2$ alleles in our studied groups, these results explained that in control group the A allele was presented in 19 (47.0\%) and the $\mathrm{G}$ allele was presented in $21(53.0 \%)$ in control group. While, in cases' group the A allele was presented in $8(20.0 \%)$ cases and the $\mathrm{G}$ allele was presented in 32 $(80 \%)$ of cases. There was a statistical significant difference between both groups with p-value: 0.009.

Our results clarified that the AA genotype was more presented in the control group (OR, 0.12; 95\% CI: 0.01-2.71), while the GG genotype was more presented in the cases group (OR, 3.45; 95\% CI: 0.7915.8) and the $G$ allele was the most presented one in the cases group than the A allele (OR, 3.6; 95\% CI: 1.211.07). These findings indicate that there are an association between the prevalence of both $\mathrm{G}$ allele and GG genotype and increased risk of chronic ITP in children.

In the study done by Yesil et al. ${ }^{(13)}$ they reported that the distribution of the three genotype groups (GG, GA, AA) was significantly different between the ITP patients and controls $(\mathrm{P}=0.025)$. Also, they reported that the GG genotype of $\mathrm{Cdx}-2$ was overrepresented in the ITP group $(84.1 \%)$ versus controls (62\%), the frequency of the Cdx-2 A allele was significantly different between ITP patients and controls and no significant differences were observed between ITP patients and controls of frequency of the Cdx-2 G allele. They concluded that the $\mathrm{Cdx}-2$ A allele was associated with a decreased risk in the ITP (OR, 0.343; 95\% CI: $0.150-0.782)$. The Cdx-2 polymorphism is located in the promoter region of VDR, and it carries a $G$ to A sequence change that affects the function of the transcription factor. The presence of the $G$ allele at the Cdx-2-binding site reduces the transcriptional activity of VDR promoter by $70 \%$ versus the A allele ${ }^{(\mathbf{1 0 , 2 1 )}}$.

These results showed that there was no significant relation between the three VDR genotypes and serum vitamin $\mathrm{D}$ levels. Also, there was no significant difference between the two alleles $A$ and $G$ regarding serum vitamin D levels with p-value: 0.606. In agreement with the findings, Yesil et al. ${ }^{(13)}$ reported that the mean serum $25(\mathrm{OH}) \mathrm{D}$ in ITP patients with the $\mathrm{Cdx}-$ 2 A allele $(20.8 \pm 8.72 \mathrm{ng} / \mathrm{mL}$; range, $11.5-37 \mathrm{ng} / \mathrm{mL})$ was not significantly different from that in ITP patients who did not have the Cdx-2 A allele $(18.68 \pm 9.18$ $\mathrm{ng} / \mathrm{mL}$; range, $4.4-46.2 \mathrm{ng} / \mathrm{mL} ; \mathrm{P}=0.576$.

In this study we compared between the 3 genotypes regarding age, gender and complete blood picture (CBC) values ( $\mathrm{Hb} \%$, WBCs, and Plts) in both groups (control and cases). This study showed that there was no significant difference between the 3 genotypes regarding the previously mentioned variables with pvalue: $0.740,0.058,0.223,0.667$ and 0.218 respectively in the control group and with p-values: 0.191, 0.79, $0.263,0.084$ and 0.442 respectively in the cases group.
Limitation of the study: Small numbers of patients and the lack of sufficient studies in the subjects of research in children.

\section{CONCLUSION}

We can conclude that significant association of vitamin $\mathrm{D}$ receptor gene $(\mathrm{Cdx} 2)$ polymorphism with chronic immune thrombocytopenic purpura in children may indicate its possible role in disease pathogenesis. Also, chronic ITP in children was found to be associated with lower level of serum vitamin D.

\section{RECOMMENDATIONS}

Vitamin D therapy is much recommended for children with chronic ITP. Genetic screening for polymorphism in ITP is strongly needed to pave the way for early detection, disease control and application of appropriate therapeutic strategies.

\section{REFERENCES}

1. Cines DB, Bussel JB, Liebman HA et al. (2009): The ITP syndrome: Pathogenic clinical diversity. Blood, 113(26):6511-6521.

2. Azevedo SJ, Monteiro FK, Tres PJ et al. (2013): Vitamin D receptor (VDR) gene polymorphisms and susceptibility to systemic lupus erythematosus clinical manifestations. Lupus, 22 (11): 1110-1117.

3. Han JJ, Baek SK, Lee JJ et al. (2010): Long-term outcomes of a 5-year follow up of patients with immune thrombocytopenic purpura after splenectomy. Korean J Hematol., 45 (3): 197-202.

4. Köstner KIM, Denzer N, Müller CSL et al. (2009): The vitamin $\mathrm{D}$ endocrine system regulates a broad variety of independent biological processes including bone metabolism. Anticancer Res., 3536: 3511-3536.

5. Labuda M, Fujiwara TM, Ross MV et al. (1992): Defects related to vitamin $\mathrm{D}$ metabolism map to the same region of human chromosome. J Bone Miner Res., 7: 1447-1453.

6. Esposito S, Lelii $M$ (2015): Vitamin D and respiratory tract infections in childhood. BMC Infect Dis., 15: 487-496.

7. Handel AE, Sandve GK, Disanto G et al. (2013): Vitamin D receptor ChIP-seq in primary CD4+ cells: Relationship to serum 25-hydroxyvitamin D levels and autoimmune disease. BMC Med., 11 (1): 1-11.

8. Hayes CE, Nashold FE, Spach KM et al. (2003): The immunological functions of the vitamin D endocrine system. Cell Moll Biol (Noisy-le-grand), 49 (2): 277-300.

9. McCullough ML, Bostick RM, Mayo TL (2009): Vitamin D gene pathway polymorphisms. Annu Rev Nutr., 29: 111-132.

10. Arai H, Miyamoto KI, Yoshida M et al. (2001): The polymorphism in the caudal-related homeodomain protein $\mathrm{Cdx}-2$ binding element in the human vitamin $\mathrm{D}$ receptor gene. J Bone Miner Res., 16: 1256-1264.

11. Chen WY, Bertone-Johnson ER, Hunter DJ et al. (2005): Associations between polymorphisms in the vitamin $\mathrm{D}$ receptor and breast cancer risk. Cancer Epidemiol Biomarkers Prev., 14: 2335-2339.

12. Fang Y, Meurs JB, Bergink AP et al. (2003): $\mathrm{Cdx}-2$ polymorphism in the promoter region of the human vitamin $\mathrm{D}$ receptor gene determines. J Bone Miner Res., 18; 9: 1632-1641.

13. Yesil S, Tanyildiz HG, Tekgunduz SA et al. (2017): Vitamin D receptor polymorphisms in immune thrombocytopenic purpura. Pediatr Int., 59: 6:682-685.

14. Čulić S, Markić J, Petrović D et al. (2016): Serum vitamin D levels in children with newly diagnosed. Semin Hematol., 1: 6769. 
15. Evim MS, Baytan B, Güneş AM (2014): Childhood Immune Thrombocytopenia: Long-term Follow-up Data Evaluated by the Criteria of the International Working Group on Immune Thrombocytopenic Purpura. Turk J Haematol., 31 (1): 32-39.

16. Saeidi S, Jaseb K, Asnafi AA et al. (2014): Immune thrombocytopenic purpura in children and adults: A comparative retrospective study in IRAN. Int J Hematol Stem Cell Res., 8 (3): 30-36.

17. Provan D, Stasi R, Newland AC et al. (2010): International consensus report on the investigation and management of primary immune thrombocytopenia. Blood, 115 (2): 168-186.
18. Neunert $C, \operatorname{Lim} W$, Crowther $M$ et al. (2011): The American Society of Hematology 2011 evidence-based practice guideline for immune thrombocytopenia. Blood, 117: 4190-4207.

19. Osman MEF (2012): Childhood immune thrombocytopenia: Clinical presentation and management. Sudan J Paediatr., 12 (1): 27-39.

20. Grimaldi-Bensouda L, Nordon C, Leblanc T et al. (2017): Childhood immune thrombocytopenia: A nationwide cohort study on condition management. Pediatr Blood Cancer, 00: 1-8.

21. Dickinson JL, Perera DI, van der Mei AF et al. (2009): Past environmental sun exposure and risk of multiple sclerosis: a role for the Cdx-2 Vitamin D receptor variant in this interaction. Mult Scler., 5: 563-570. 